\title{
Modeling of Consumer Preferences and Constraints for the Optimal Schedule of Consumption Shifting
}

\author{
Pedro Faria, João Spínola, and Zita Vale \\ Polytechnic of Porto \\ Porto, Portugal \\ pnf@isep.ipp.pt;jspin@isep.ipp.pt;zav@isep.ipp.pt
}

\begin{abstract}
The actual context for smart grid implementation implies the development of tools to support the diverse player's decisions. The present paper addresses a multi-period consumer's management methodology for the scheduling of demand flexibility initiatives and on-site generation. The objective is to minimize the energy costs for the consumer, taking into account his resources. The paper also considers the use of dynamic pricing with the intent of studying its effect on load shifting schedule. The results obtained show how the consumers can use this methodology to achieve new efficiency levels regarding their energy use, and therefore costs.
\end{abstract}

Index Terms-- demand response, distributed generation, load shifting, resource scheduling.

\section{NOMENCLATURE}

Indexes:

$S \quad$ Total number of external suppliers

$P \quad$ Total number of distributed generators

C Total number of consumers

$T \quad$ Total number of periods

Variables:

$P_{(p, t)}^{D G} \quad$ Amount of energy acquired from on-site or

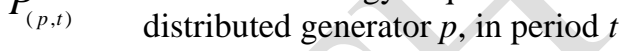

$P_{(s, t)}^{\text {Sup }} \quad$ Amount of energy acquired from external supplier

$P_{(s, t)} \quad s$, in period $t$

$P_{(c, t)}^{\text {Shift }} \quad$ Amount of load reduction made by the consumer $c$,

$(c, t, t) \quad$ in period $t$

$P_{(c, t, d)}^{\text {Shift }}$ Amount of load shifting made by the consumer $c$,

$P_{(c, t, d)} \quad$ from period $t$ to period $d$

Parameters:

$\begin{array}{ll}C_{(p, t)}^{D G} & \text { Linear cost for the on-site or distributed generator } \\ & p \text {, in period } t\end{array}$

$C_{(s, t)}^{\text {Sup }} \quad$ Cost of the external supplier $s$, in period $t$

$P_{(c, t)}^{\text {Base }} \quad$ Amount of expected consumption from consumer

The present work was done and funded in the scope of the following projects: COLORS Project PTDC/EEI-EEE/28967/2017 and UID/EEA/00760/2019 funded by FEDER Funds through COMPETE program and by National Funds through FCT.

\section{INTRODUCTION}

The introduction of smart grid measures implies a great deal of technology and energy awareness that isn't always easy to attain [1]. So that smart grid measures implementation is made simpler, tools have to be provided that guarantee efficiency but at the same time rise awareness to the producers and consumers [2], [3]. In the smart grid context, consumers gain a new meaning, by becoming an active part of the power systems management, acting as a resource providing flexibility [4]. The energy flexibility of a consumer can be defined as the capacity of modifying its energy consumption in a short time horizon, during a given period. Usually, the resources providing flexibility are renewable energy sources (e.g. wind turbines, Distributed Generation - DG) and consumers (participating in Demand Response programs DR) [5]-[7]. These are resources that can change very quickly their output and thus acting almost as a reserve generator that the operator may call in times of need, however, without the high maintenance costs that are normally associated with the use of diesel generators in standby. The consumer, in order to participate at this kind of level, has to be in a program contract with the transmission or distribution operator, or any other entity that is available to provide such programs [8]. However, it is also important for the consumer to be able to perform demand response programs on its own without any contractual features [9], and therefore there is the need for a tool capable of supplying a management methodology to perform cost minimization regarding the consumption made [10].

The load reduction programs are amongst the most implemented around the world, since they represent an easy way to communicate and act in the consumer, however, there are still difficulties known regarding the loss of load and the types of consumers capable of doing it [11].

The load shifting programs are usually very complex and difficult to implement, since there is always a conflict of interests regarding the transfer of load between periods (e.g. the transfer of part of an industrial process) [12], [13]. In order to change consumption habits, peak pricing and time-of-use programs (dynamic pricing) are amongst the most used. In these programs, the consumer will pay more for consuming 
energy in periods where overall consumption is high, thus the costs are higher and the consumer is encouraged to become more aware and efficient regarding its consumption [14].

In the present paper, a methodology for dealing with consumer's energy management is proposed, by addressing the scheduling of a building considering different types of demand response and supply options. Other research papers addressing the consumer's perspective can be found in [15][19]. The present work is a development upon [20], with the following improvements and contributions:

- The methodology is placed from a consumer's perspective instead of a virtual power player's or aggregator;

- Address the effects of dynamic pricing together with demand response strategies, encouraging shifting actions;

- Introduce parameterization options to the scheduling regarding the use of resources and consumer's choices;

- Define consumer's decisions regarding the load shifting schedule, by introducing weights in the objective function;

After this introductory section, the next chapter presents the proposed methodology (Section II), while in Section III it is shown the mathematical formulation, followed by the case study in Section IV. The results for the scheduling and scenarios considered are presented in Section V, and finally the conclusions are in Section VI.

\section{PROPOSED METHODOLOGY}

The methodology needs information on the available resources and their characteristics, including knowledge about consumption tariffs, energy prices for production, amongst others, in order to optimally perform the cost minimization for the consumer. In Figure 1, the proposed methodology is present regarding a consumer's management tool.

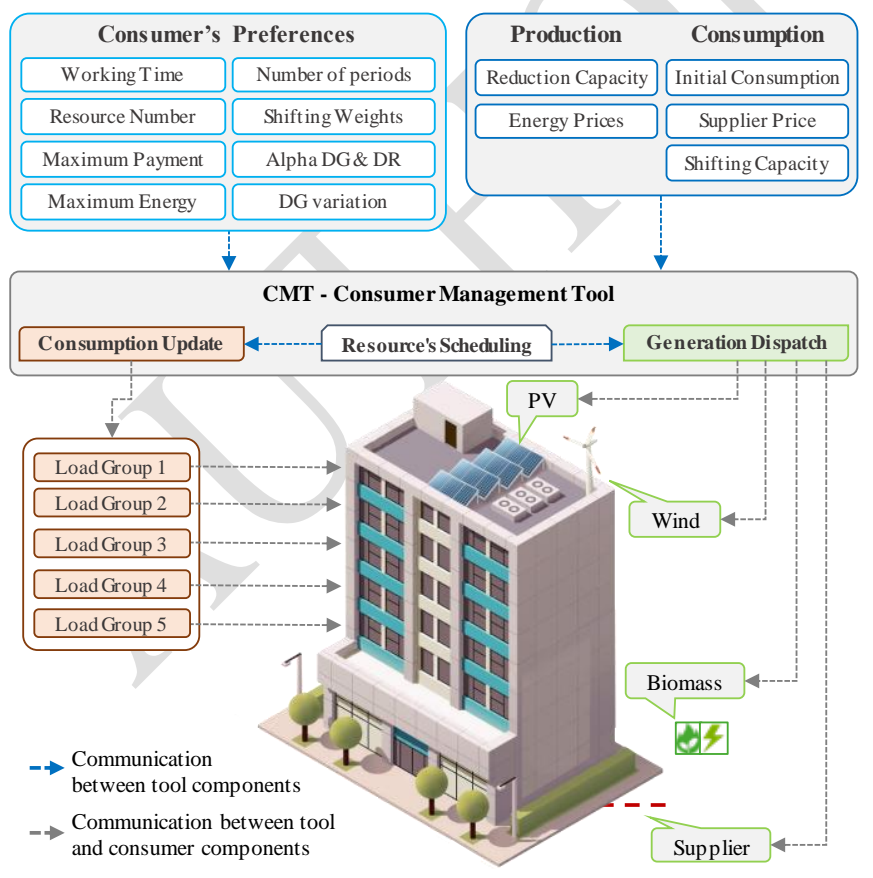

Figure 1. Proposed methodology.
The tool performs the scheduling according to the preferences chosen and the minimization of costs. After this decision, the consumption is updated and the generation dispatch is communicated to producers, implementing the scheduling in real applications.

There is two types of communication that go through the methodology, between tool components (resource's characteristics and consumer's preferences) and between tool and external components (update and dispatch actions after scheduling). Regarding production, the consumer's management tool takes into account the maximum capacity of the on-site and distributed generators, and their costs. In what concerns consumption, it is important to know the capacities for load shifting, as well as the initial load expected for the periods considered, and the prices related to consumption, that in this case, are considered to be dynamic. Although single tariff programs can be also performed by the methodology, the authors choose to apply dynamic tariffs in order to reinforce the load shifting capabilities when dealing with this type of payment that allows savings for the consumer if well managed. The methodology takes into account a single consumer that has five load groups. These represent aggregated loads from the several equipment belonging to the building. The consumer's management methodology, taking into consideration the possibilities of demand response, and the on-site or distributed generation, will perform the minimization of costs, from the purchase of energy from the network - seen in this case as the external suppliers.

The number of periods allows the methodology to enable shifting possibilities between them. The shifting weights serve as an indicator of the most willing periods that a given load group can shift load amounts. Additionally, the following features present the consumer preferences, as an innovation regarding the work presented in [20]:

- The DG and supplier "working time" represents the minimum number of periods that each of these resources are to be scheduled;

- The DG and supplier "resource number" represents the maximum number of these resources that are to be scheduled in a given period;

- The "DG variation" represents the maximum increase or decrease of the energy scheduled for each distributed generator, in a given period compared with previous one;

- The "maximum payment" is the monetary amounts that the consumer can expend for the resources used;

- The "maximum energy" concerns the same concept as the maximum payment, but in terms of energy;

- The "Alpha DG \& DR" represent limits in percentage regarding the total energy scheduled for those types of resources. In the case of alpha DR, this limit represents the maximum percentage of each load group regarding the total amount shifted.

In this way, the present work proposes a methodology that implements demand response in a given consumer, at the same time that considers generation resources to optimize load consumption and therefore reduce energy costs. 


\section{FORMULATION}

One the major contributions in the present paper is the given possibility for the consumer to define preferences regarding the scheduling of the available resources, and of its own capabilities in what concerns demand response - these considerations are approached further on in the paper, through equations (12)-(20). Firstly, we aim to minimize the consumer's energy cost, since the methodology is seen from its perspective, as in eq. (1).

\section{Minimize}

$$
\begin{aligned}
& F=\sum_{p=1}^{P} P_{(p, t)}^{D G} \cdot C_{(p, t)}^{D G}+\sum_{c=1}^{C} \sum_{d=1}^{T} P_{(c, t, d)}^{\text {Shift }} \cdot W_{(c, t, d)}^{\text {Shift }} \\
& +\sum_{s=1}^{S} P_{(s, t)}^{\text {Sup }} \cdot C_{(s, t)}^{\text {Sup }}, \quad \forall t \in\{1, \ldots, T\}
\end{aligned}
$$

The network's balance must be kept at all times, therefore equation (2) is implemented considering each resource's contribution. Due to space limitations in this paper, the remaining equations are described and mentioned but not actually illustrated

$$
\begin{aligned}
& \sum_{s=1}^{S} P_{(s, t)}^{\text {Sup }}+\sum_{p=1}^{P} P_{(p, t)}^{D G}=\sum_{c=1}^{C}\left(\begin{array}{l}
P_{(c, t)}^{\text {Base }}+ \\
\left.\sum_{d=1}^{T}\left[\begin{array}{l}
P_{(c, d, t)}^{\text {Shift }}-P_{(c, t, d)}^{\text {Shift }} \\
-P_{(c, t, t)}^{\text {Shift }}
\end{array}\right]\right)
\end{array}\right) \\
& \forall t \in\{1, \ldots, T\}
\end{aligned}
$$

The next equation (3) presents the limits for shifting transactions, i.e. the amount of energy that can be transferred from a period to another. As for equations (4) and (5), these limit the total energy transfer into or from a given period, respectively, i.e. the total energy that a consumer can shift from a period to all others, and the energy that can be transferred into a given period from all others. In equation (6), the limitation of demand response is made, allowing to model the consumer comfort. In some occasions, it is important to limit the use of demand response considering the total scheduling values and the consumer that will be affected by it, e.g. priority consumption that cannot be affected by demand response measures. In this way, equation (7) presents the consumer shifting out (from a given period into all others) regarding the other consumers, i.e. the limitations to each consumer's shifting contribution. Regarding the producers, their production capacities are taken into account in equations (8) and (9).

Now it comes an important feature of the proposed methodology: the consumer's perspective and expected savings. Taking into account the existing contract between a consumer and the grid (either with static or dynamic tariffs), this is the origin of the consumer's higher costs regarding energy consumption. In this way, the consumer's consumption amount that needs to be supplied by the energy contract, is given by equation (10), where the amount of energy needed is equal to the consumer's consumption subtracted by the actuation of demand response initiatives and distributed or onsite generation. Similar to equation (6), in equation (11) it is presented the limitation of distributed generation contribution into the final scheduling. While equation (6) presents a limitation inside a given type of resource, equation (11) presents a limitation considering all resources.

In equations (12) and (13) the binary variable assume the value one for a producer $s$ or $p$ in a given period $t$, if it is scheduled to be used by the consumer, and the value zero if it is not. Now considering the number of times that a given resource has been used during the timeline considered (total number of periods), equations (14) and (15) make possible to limit or oblige a certain number of usages for any or each resource. Equation (16) defines the maximum energy that varies in a given period from the previous one. Regarding equations (17) -(18), these limit the total remuneration of external suppliers, and to distributed/on-site generators. This ensures that the producers are not remunerated and used a higher amount than defined by the consumer.

Equations (19) and (20) detail a similar concept to what is intended with equations (17) and (18), however, regarding the total energy used from distributed generators and external suppliers, considering all periods. In this paper, the consumer preferences in the first three scenarios are 4 and 6 for the minimum number of external suppliers and distributed generators to participate in each period, respectively. The minimum amount of the times that each generation resource can participate is 0 (being possible up to 24 times). The maximum variation for distributed generators is equal to 200 $\mathrm{kWh}$, while their maximum simulation cost and energy is 1x106 m.u. and 1x106 kWh, respectively. The same values are considered for what is related with external suppliers.

\section{CASE STUdy}

This case study is inspired in the one presented in [20], i.e. it is considered that the five load groups represent floors from an office building and can be managed by a consumer's management tool. The generators considered and shown in Table I, are mostly on-site generation, but also several types of external suppliers. In, the resources are divided by a thick black line, where the upper resources are external suppliers, and the lower resources are on-site generation. The generation capacity is shown by Figure 2.

TABLE I. GENERATION SOURCE'S CHARACTERISTICS AND COSTS

\begin{tabular}{c|c|c|c}
\hline \hline $\begin{array}{c}\text { Generator } \\
\text { Type }\end{array}$ & $\begin{array}{c}\text { Linear } \\
(\mathrm{m} . \mathrm{u} . / \mathrm{kWh})\end{array}$ & $\begin{array}{c}\text { Production } \\
\text { Peak }(\mathrm{kWh})\end{array}$ & Contribution $(\%)$ \\
\hline \hline Coal & & 1170.8 & 17.25 \\
\cline { 1 - 3 } Fuel (Diesel) & \multirow{2}{*}{ dynamic } & 0.0 & 0.00 \\
\cline { 3 - 4 } Natural Gas & & 413.6 & 4.03 \\
\cline { 3 - 4 } & & 1088.2 & 6.21 \\
\hline Hydro & 0.06 & 486.1 & 2.36 \\
\hline DG-Hydro 1 & 0.12 & 2077.3 & 18.47 \\
\hline DG-PV 1 & 0.06 & 88.2 & 0.82 \\
\hline DG-Hydro 2 & 0.12 & 1094.1 & 16.51 \\
\hline DG-CHP & 0.04 & 2842.3 & 33.74 \\
\hline DG-Wind & 0.02 & 121.9 & 0.61 \\
\hline DG-PV 2 & & &
\end{tabular}




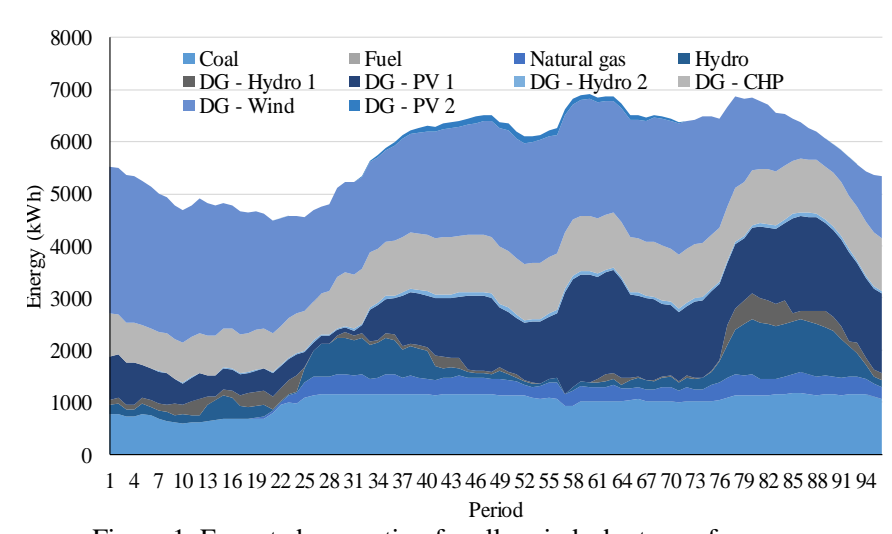

Figure 1. Expected generation for all periods, by type of resource.

Table II details the consumption prices for the load group's, considering the several periods. Dynamic tariffs are used. The use of this type of energy prices allows several interesting approaches regarding the gain of awareness by the consumer in terms of efficient energy consumption. The total consumption, along each period is shown by Figure 3 .

TABLE II. CONSUMER'S CHARACTERISTICS AND TARIFFS

\begin{tabular}{|c|c|c|c|c|c|}
\hline $\begin{array}{l}\text { \# Load } \\
\text { Group }\end{array}$ & $\begin{array}{l}\text { Peak Tariff } \\
\text { (m.u./kWh) }\end{array}$ & $\begin{array}{l}\text { Peak } \\
\text { Periods }\end{array}$ & $\begin{array}{c}\text { Off-Peak } \\
\text { tariff } \\
\text { (m.u./kWh) }\end{array}$ & $\begin{array}{c}\text { Off-Peak } \\
\text { periods }\end{array}$ & $\begin{array}{c}\text { Peak load } \\
\text { (kWh) }\end{array}$ \\
\hline 1 & 0.20 & \multirow{5}{*}{$\begin{array}{c}1-9,21- \\
39,71- \\
96\end{array}$} & 0.120 & \multirow{5}{*}{$\begin{array}{l}10-20 \\
40-70\end{array}$} & 32.32 \\
\hline 2 & 0.18 & & 0.108 & & 20.97 \\
\hline 3 & 0.16 & & 0.096 & & 16.23 \\
\hline 4 & 0.19 & & 0.114 & & 21.24 \\
\hline 5 & 0.12 & & 0.072 & & 9.23 \\
\hline
\end{tabular}

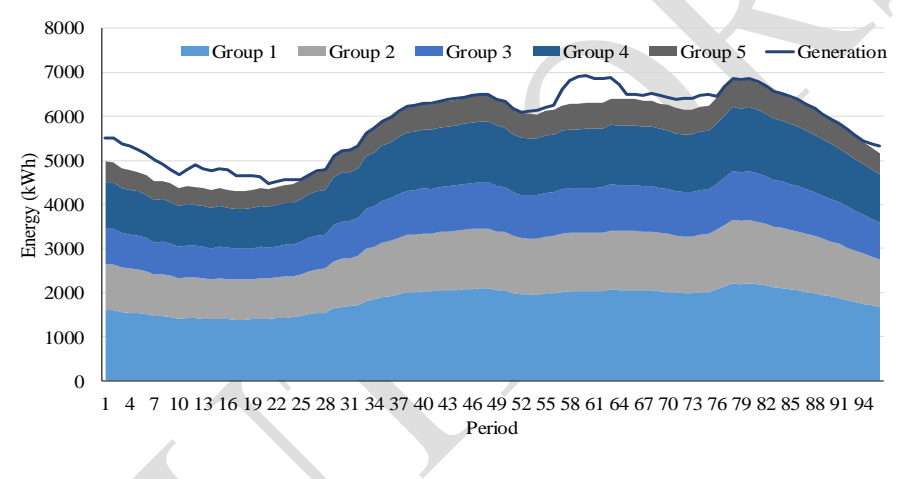

Figure 2. Baseline consumption for all periods, by load group.

As one can see by Table II, the load groups present distinct prices for the use of energy, taking into consideration that the characteristics of each one are also different. In this case study, one considers that the low tariffs applied in the off-peak periods, corresponds to an attenuation of 60 percent when compared with the tariffs applied in the peak periods.

The load shifting approaches will be analyzed taking into account the shifting priorities (see Table III). The priorities were considered the same for all load groups and therefore there isn't any special feature of any given load group. In this way, Table III shows the possible combinations and the values of priorities chosen, that will represent an additional cost in the consumer's management. To represent the priorities combinations, one serves as input a T-by- $\mathrm{T}$, that in this case equals 96 (a day in measurements with a sampling time of 15 minutes). In order to be easier to explain, the matrix is classified by parts, namely, under, main, and above diagonal, as in Table III. The numbers represent the combinations, e.g. when displayed " $60 \rightarrow 38: 81 \rightarrow 59$ ", this means that the priority level one (0.001) is the value applied to the shifting amount that is transferred from period 60 to 38 , the same until what is transferred from period 81 to 59 , proportionally.

\section{TABLE III. SHIFTING PRIORITIES}

\begin{tabular}{|c|c|c|c|}
\hline Weights & $\begin{array}{c}\text { First level } \\
(0.001)\end{array}$ & $\begin{array}{c}\text { Second level } \\
(0.01)\end{array}$ & $\begin{array}{c}\text { Third level } \\
\text { (5) }\end{array}$ \\
\hline $\begin{array}{c}\text { Under } \\
\text { Diagonal }\end{array}$ & $\begin{array}{l}60 \rightarrow 38: 81 \rightarrow 59 \\
71 \rightarrow 38: 92 \rightarrow 59\end{array}$ & $\begin{array}{l}30 \rightarrow 5: 54 \rightarrow 15 \\
65 \rightarrow 16: 89 \rightarrow 26 \\
35 \rightarrow 34: 59 \rightarrow 58\end{array}$ & $\begin{array}{l}\text { All other } \\
\text { combinations }\end{array}$ \\
\hline Diagonal & $1 \rightarrow 1: 96 \rightarrow 96$ & - & - \\
\hline $\begin{array}{c}\text { Above } \\
\text { Diagonal }\end{array}$ & $\begin{array}{c}7 \rightarrow 37: 18 \rightarrow 58 \\
28 \rightarrow 37: 39 \rightarrow 58\end{array}$ & $\begin{array}{c}8 \rightarrow 70: 32 \rightarrow 80 \\
42 \rightarrow 81: 66 \rightarrow 91 \\
33 \rightarrow 34: 57 \rightarrow 58\end{array}$ & $\begin{array}{c}\text { All other } \\
\text { combinations }\end{array}$ \\
\hline
\end{tabular}

The scheduling will include three scenarios: A (load shifting weights are disabled), B (shifting weights are as in Table III), and C (using of limiters of equations (17)-(20)). In scenario A, the load shifting weights are disabled. In scenario $\mathrm{B}$, one considers the implementation of both shifting weights and consumer preference equations, therefore seeing the conflict of interests between the maintenance of a certain onsite generation degree and the different shifting possibilities (most and less attractive). This means that the willing or convenience to shift load between periods differs and is dependent on which period one is addressing. Finally, scenario $\mathrm{C}$ adds the usage of limiters to scenario $\mathrm{B}$.

\section{RESULTS}

\subsection{Scenario A}

In scenario $A$, the shifting priorities are not considered, and thus it is assumed that weights of all the combinations are zero. Moreover, this means an incentive to the use of load shifting since no cost is considered, which makes sense in a consumer's management methodology, since the consumer's own consumption is free to be modified by himself. In this way, this scenario includes a wider resource's application by considering a free shifting capacity and consumer preferences restraints, where the latter serves as: working time that each of these resources are to be scheduled - equation (12) and (13), number for each type of production resource to be scheduled equation (14) and (15), variation limit to the energy acquired from distributed generation - equation(16), limits in total payments - equations (17) and (18) - and energy for each type of resource - equations (19) and (20). In Figure 4, it is presented the resource's scheduling for scenario A conditions. In this first scenario, the majority of consumption is met by the distributed generation resources. 


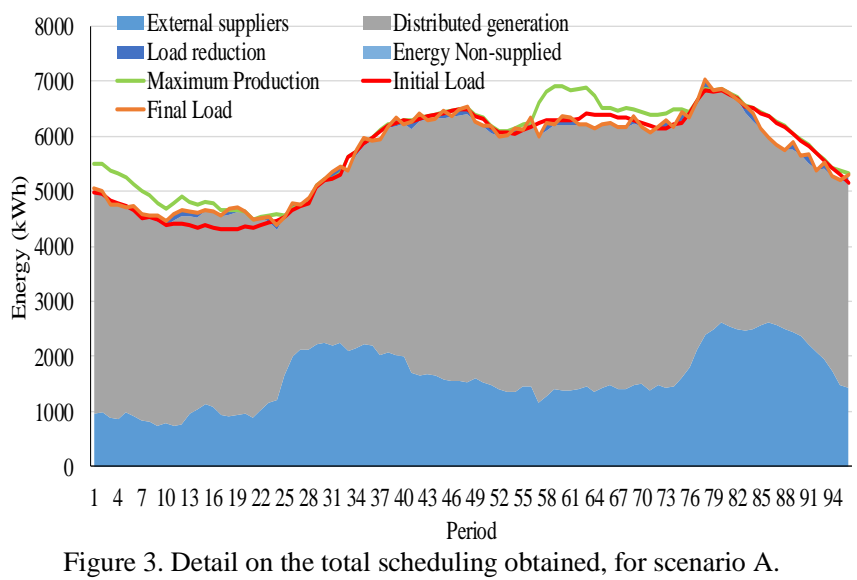

It is also clear the contribution of energy reductions together with load shifting to improve the scheduling, namely, in what concerns variations occurred between the initial and final load, as shown in Figure 5.

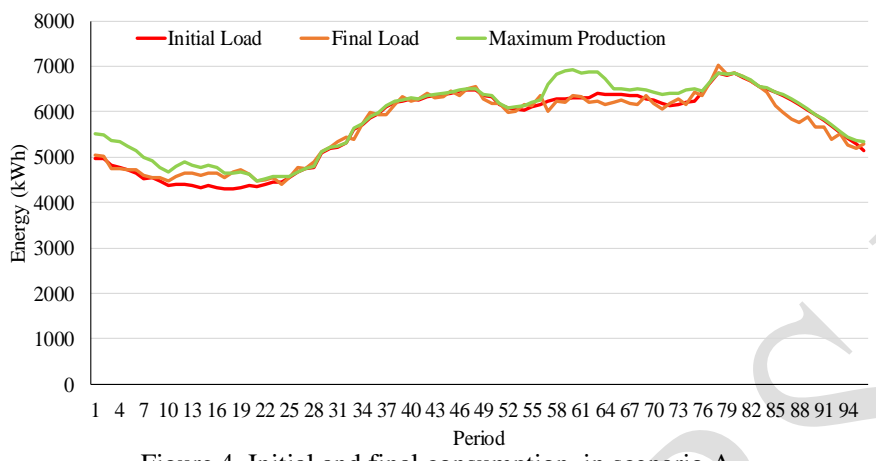

Figure 4. Initial and final consumption, in scenario A.

Now considering the energy consumption, initial and final, in more detail - Figure 5. Some differences are noticeable namely, in terms of periods chosen to shift load. In Figure 6, it is detailed the shifting energy amongst the periods for scenario A. One can see that much more changes have been made when compared with the first scenario results, regarding the number of periods where shifting is made, since all periods received and sent load amounts from and to others.

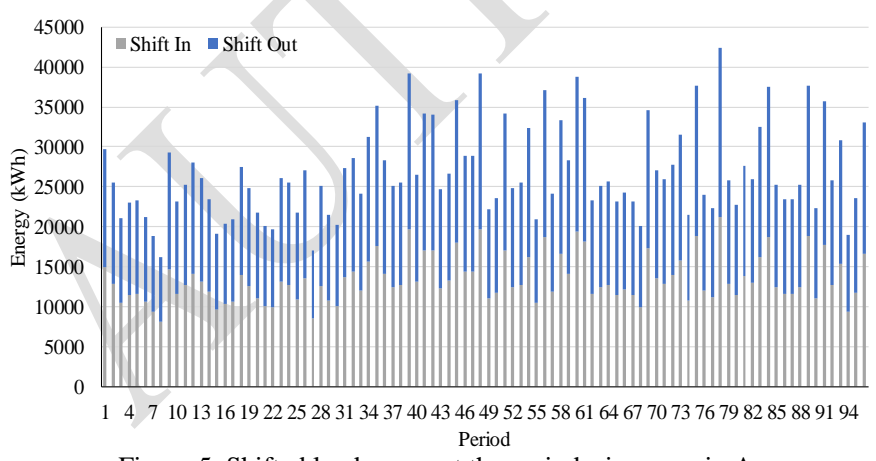

Figure 5. Shifted load amongst the periods, in scenario A.

\subsection{Scenario B}

In this second scenario (scenario B), one will consider different weights for the scheduling, incenting to perform shifting more in some periods than in others. The characteristics of the other resources remain the same, and therefore the scheduling obtained is as shown by Figure 7, where one can see once again the high penetration of distributed generation resources, however, this is explained since the cost of it is static, as described in Table III. In the external supplier's case, the price is dynamic and varies as in Table II. The external suppliers were used to provide the remaining energy needed besides the DG contribution, and in some periods there is available generation, as in Figure 8. In this way, the decisive factors are on the consumption side, namely, in the shifting capacity/cost and in the consumer preferences equations that limit the payment. By using these conditions, the scheduling is made for cost minimization, thus in this way becoming clear the influence that the shifting priorities has in the consumer's scheduling. In Figure 9, the shifting amounts are presented concerning scenario B, and one can see that the shifting priorities are clearly seen since the periods where the most shifting amounts are located, are related to the periods where the priorities are lower (then more attractive to the scheduling), as in Table III.

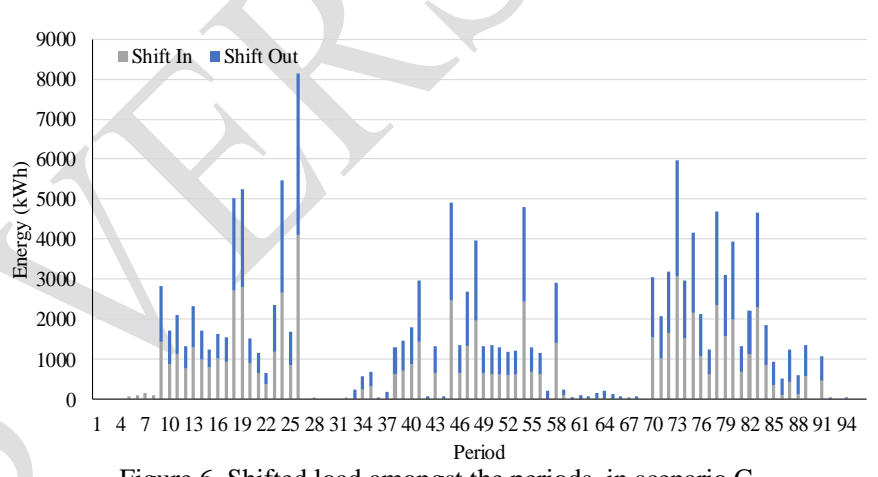

Figure 6. Shifted load amongst the periods, in scenario C.

\subsection{Scenario $C$}

In this scenario one addresses the influence of remuneration and energy limiters - equations (17) and (20) in the usage of shifting amounts. The results are shown in Figure 10 regarding the shifting amount scheduled. As one can see the reduction of remuneration amounts (main axis - grey) for external suppliers and distributed generators, causes a raise in the usage of shifting flexibility.

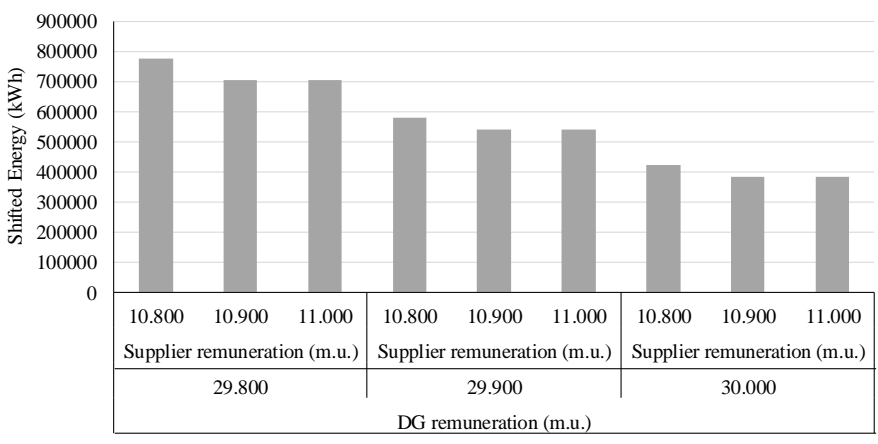

Figure 7. Shifting scheduled versus remuneration preferences.

\subsection{Comparison of scenarios}

The comparison is as shown in Table IV. One can see by the results that scenario $\mathrm{A}$ is the least costly for the consumer, however, one must consider that this scenario implies that load 
shifting has no restraints considering where to move load. However, the differences between the remuneration and energy scheduled are not considerable, so the consumer can choose the scenario B in case it needs to define certain periods to shift load. The same results for scenario $\mathrm{C}$ are also presented, considering a chosen variation from the all demonstrated before. In this case, some results are already acquired at the beginning due to the scenario's conditions.

One can see, when comparing scenario B and C, that the lower payments were made to production resources, namely, distributed generators and suppliers, however, is easily seen that the energy shifted is much larger, thus respecting perhaps less of the weights considered. When addressing the comparison between scenario $\mathrm{A}$ and $\mathrm{C}$, one can conclude that less payment and energy is obtained from distributed generators, but more energy is bought from external suppliers, thus increasing the expenses with grid energy, however, much less energy was shifted amongst the different periods.

TABLE IV. SCENARIO COMPARISON

\begin{tabular}{l|c|c|c}
\cline { 2 - 4 } & \multicolumn{3}{|c}{ Scenario } \\
\cline { 2 - 4 } & $\mathrm{A}$ & $\mathrm{B}$ & $\mathrm{C}$ \\
\hline \hline $\begin{array}{l}\text { Energy scheduled from external } \\
\text { suppliers (kWh) }\end{array}$ & 134980 & 141450 & 139000 \\
\hline Energy scheduled from DG (kWh) & 405480 & 403990 & 403000 \\
\hline $\begin{array}{l}\text { Energy scheduled from load shifting } \\
\text { (kWh) }\end{array}$ & 1166800 & 7512 & 526000 \\
\hline Payment to external suppliers (m.u.) & 9448 & 9901 & 9730 \\
\hline Payment to DG (m.u.) & 32069 & 31890 & 31771 \\
\hline
\end{tabular}

\section{CONCLUSIONS}

In the present paper, is proposed a methodology for an individual consumer to manage its consumption, making use of several distinct resources, including its own capabilities. The latter refers to demand response initiatives, namely, load reduction and shifting. Results show that the introduction of weights to define period priorities in the scheduling, allows the consumer to have more control over the load shifting possibilities, and thus improve even further its operation. Also, by adopting reduction strategies, it is possible to raise energy consumption efficiency, since no priority loads are affected. The inconsideration of the consumer's load profile and consumption needs allows reduced costs and energy from production-side, although considerable amounts of energy need to be shifted, in order to take advantage of reduced prices caused by dynamic pricing.

\section{REFERENCES}

[1] R. Bayindir, I. Colak, G. Fulli, and K. Demirtas, "Smart grid technologies and applications," Renew. Sustain. Energy Rev., vol. 66, pp. 499-516, Dec. 2016.

[2] S. Bigerna, C. A. Bollino, and S. Micheli, "Socio-economic acceptability for smart grid development - a comprehensive review," J. Clean. Prod., vol. 131, pp. 399-409, Sep. 2016.

[3] O. Ellabban and H. Abu-Rub, "Smart grid customers' acceptance and engagement: An overview," Renew. Sustain. Energy Rev., vol. 65, pp. 1285-1298, Nov. 2016.

[4] C. Eid, P. Codani, Y. Perez, J. Reneses, and R. Hakvoort, "Managing electric flexibility from Distributed Energy Resources: A review of incentives for market design," Renew. Sustain. Energy Rev., vol. 64, pp. 237-247, Oct. 2016.

[5] S. Feuerriegel and D. Neumann, "Integration scenarios of Demand Response into electricity markets: Load shifting, financial savings and policy implications," Energy Policy, vol. 96, pp. 231-240, Sep. 2016.

[6] J. M. Roldán Fernández, M. Burgos Payán, J. M. Riquelme Santos, and Á. L. Trigo García, "Renewable generation versus demand-side management. A comparison for the Spanish market," Energy Policy, vol. 96, pp. 458-470, Sep. 2016

[7] B. P. Esther and K. S. Kumar, "A survey on residential Demand Side Management architecture, approaches, optimization models and methods," Renew. Sustain. Energy Rev., vol. 59, pp. 342-351, Jun. 2016.

[8] K. Muralitharan, R. Sakthivel, and Y. Shi, "Multiobjective optimization technique for demand side management with load balancing approach in smart grid," Neurocomputing, vol. 177, pp. 110-119, Feb. 2016.

[9] A. R. Khan, A. Mahmood, A. Safdar, Z. A. Khan, and N. A. Khan, "Load forecasting, dynamic pricing and DSM in smart grid: A review," Renew. Sustain. Energy Rev., vol. 54, pp. 1311-1322, Feb. 2016.

[10] J. Hong, C. Johnstone, J. Torriti, and M. Leach, "Discrete demand side control performance under dynamic building simulation: A heat pump application,” Renew. Energy, vol. 39, no. 1, pp. 85-95, Mar. 2012.

[11] J. Aghaei and M.-I. Alizadeh, "Demand response in smart electricity grids equipped with renewable energy sources: A review," Renew. Sustain. Energy Rev., vol. 18, pp. 64-72, 2013.

[12] D. Patteeuw, G. P. Henze, and L. Helsen, "Comparison of load shifting incentives for low-energy buildings with heat pumps to attain grid flexibility benefits," Appl. Energy, vol. 167, pp. 80-92, Apr. 2016.

[13] X. Han, T. Ji, Z. Zhao, and H. Zhang, "Economic evaluation of batteries planning in energy storage power stations for load shifting," Renew. Energy, vol. 78, pp. 643-647, Jun. 2015.

[14] F. Kamyab and S. Bahrami, "Efficient operation of energy hubs in time-of-use and dynamic pricing electricity markets," Energy, vol. 106, pp. 343-355, Jul. 2016.

[15] D. Christantoni, S. Oxizidis, D. Flynn, and D. P. Finn, "Implementation of Demand Response Strategies in a Multi-Purpose Commercial Building using a Whole-Building Simulation Model Approach,” Energy Build., 2016.

[16] F. Fernandes, H. Morais, Z. Vale, and C. Ramos, "Dynamic load management in a smart home to participate in demand response events," Energy Build., vol. 82, pp. 592-606, 2014.

[17] F. Pallonetto, S. Oxizidis, F. Milano, and D. Finn, "The effect of timeof-use tariffs on the demand response flexibility of an all-electric smart-grid-ready dwelling," Energy Build., vol. 128, pp. 56-67, 2016.

[18] M. P. McHenry and D. Doepel, "The 'low power' revolution: Rural off-grid consumer technologies and portable micropower systems in non-industrialised regions," Renew. Energy, vol. 78, pp. 679-684, Jun. 2015.

[19] A. N. Menegaki, "A social marketing mix for renewable energy in Europe based on consumer stated preference surveys," Renew. Energy, vol. 39, no. 1, pp. 30-39, Mar. 2012.

[20] P. Faria, Z. Vale, and J. Baptista, "Constrained consumption shifting management in the distributed energy resources scheduling considering demand response," Energy Convers. Manag., vol. 93, pp. 309-320, Mar. 2015. 